\title{
Influence of rhBMP-2 on bone formation and osseointegration in different implant systems after sinus-floor elevation. An in vivo study on sheep
}

\author{
Ralf GUTWALD, MD, DDS, PhD ${ }^{1, *}$, Jörg HABERSTROH, $\mathrm{PhD}^{2, *}$, Andres STRICKER, MD, DDS ${ }^{1}$, \\ Eva RÜTHER, DMD ${ }^{1}$, Florian OTTO, MD ${ }^{1}$, Samuel Porfirio XAVIER, DDS, $\mathrm{PhD}^{3}$, Toshiyuki OSHIMA, DDS ${ }^{1,4}$, \\ E. MARUKAWA, DDS, $\mathrm{PhD}^{5}$, I. SETO, DDS, $\mathrm{PhD}^{5}$, S. ENOMOTO, DDS, $\mathrm{PhD}^{5}$, \\ Christiaan F HOOGENDIJK, MBChB, BChD, MChD, FCMFOS(SA), Dipodont ${ }^{6}$, Rainer SCHMELZEISEN, MD, \\ DDS, $\mathrm{PhD}^{1}$, Sebastian SAUERBIER, MD, DDS ${ }^{1}$ \\ ${ }^{1}$ Department of Oral and Maxillofacial Surgery, University of Freiburg, Germany; ${ }^{2}$ Division of Experimental Surgery, \\ BioMed Center, University Hospital Freiburg, Germany; ${ }^{3}$ Department of Oral and Maxillofacial Surgery, University of \\ Sao Paulo, Ribeirao Preto, Brazil; ${ }^{4}$ Faculty of Health Sciences, Institute for International Cooperation, Okayama, \\ Japan; ${ }^{5}$ Division of Oral Health Sciences, Department of Oral Restitution, Tokyo Medical and Dental University, Tokyo, \\ Japan; ${ }^{6}$ Department of Maxillofacial and Oral Surgery, Oral and Dental Hospital, University of Pretoria, Pretoria, \\ South Africa
}

SUMMARY. Background: Several studies have reported certain bone morphogenic proteins (BMPs) to have positive effects on bone generation. Although some investigators have studied the effects of human recombinant BMP (rhBMP-2) in sinus augmentation in sheep, none of these studies looked at the placement of implants at the time of sinus augmentation. Furthermore, no literature could be found to report on the impact that different implant systems, as well as the positioning of the implants had on bone formation if rhBMP-2 was utilized in sinus-lift procedures. Purpose: The aim of this study was to compare sinus augmentation with rhBMP-2 on a poly-D, L-lactic-co-glycolic acid gelatine (PLPG) sponge with sinus augmentation with autologous pelvic cancellous bone in the maxillary sinus during the placement of different dental implants. Materials and methods: Nine adult female sheep were submitted to bilateral sinus-floor elevation. In one side (test group) the sinus lift was performed with rhBMP-2 on a PLPG-sponge, while the contralateral side served as the control by using cancellous bone from the iliac crest. Three different implants (Bränemark ${ }^{\circledR}, 3 i^{\circledR}$ and Straumann $^{\circledR}$ ) were inserted either simultaneously with the sinus augmentation or as a two staged procedure 6 weeks later. The animals were sacrificed at 6 and 12 weeks for histological and histomorphometrical evaluations during which boneto-implant contact (BIC) and bone density (BD) were evaluated. Results: BD and BIC were significantly higher at 12 weeks in the test group if the implants were placed at the time of the sinus lift $(p<0.05)$. No difference was observed between the different implant systems or positions. Conclusions: The use of rhBMP-2 with PLPG-sponge increased BIC as well as BD in the augmented sinuses if compared to autologous bone. Different implant systems and positions of the implants had no effect on BIC or BD. (C) 2010 European Association for Cranio-Maxillo-Facial Surgery

Keywords: rhBMP-2, bone formation, sinus floor augmentation, titanium implant, osseointegration, sheep

\section{INTRODUCTION}

With the development of dental implants that marked a milestone in prosthodontic surgery the interest in bone augmentative procedures of the sinus floor increased dramatically (Smiler et al., 1992). The standard surgical technique for sinus-floor elevation involves raising the sinus mucous membrane and filling the cavity with either bone or biomaterials, or a combination of these. The materials utilized comprise of autogenous bone (Thorwarth et al., 2005), allogenous bone

First and second author contributed equally.
(Choukroun et al., 2008), xenogenous substitutes (Beloti et al., 2008), synthetic materials (Froum et al., 2008) or a combination of these materials (Kirmeier et al., 2008). Regardless of increased morbidity (Silva et al., 2006), autogenous bone is still the gold standard for reconstructive procedures (Raghoebar et al., 1993). Although complications such as bleeding, infection, parasthesia, fractures and pain have been described, iliac crest cortico-cancellous bone is the most suitable tissue in the reconstruction of large defects due to sufficient quantities available during harvesting (Arrington et al., 1996; Cricchio and Lundgren, 2003).

Bone induction with the aid of osteogenic precursor cells could decrease the risks and morbidity associated with 
a donor site. Alternatives for autogenous transplantation can be created by Tissue Engineering by means of the proliferation of autogenous osteoblast-like cells in combination with growth factors and biomaterials to generate functional tissues.

The group of bone morphogenic proteins (BMPs) was discovered by Urist (1965). Currently at least 20 different BMPs are reported in the literature (Wozney, 2002). Human recombinant BMP (rhBMP-2) can be produced commercially by cloned Chinese Hamster Ovary cells (CHO)-Cells (Wang et al., 1990; Wozney, 2002) or by E. coli bacteria (Kübler et al., 1998). RhBMP-2 has been tested in many studies and showed osseoinductive effects (Raghoebar et al., 1993; Boyne and Shabahang, 2001; Schwartz et al., 2008).

Yonezawa et al. (2006) evaluated the effect of rhBMP2 on bone consolidation of distraction osteogenesis in rabbit mandibles and observed that the addition of BMP promotes better bone formation. Moreover the application of BMP in irradiated rat mandibles resulted in predictable bone generation (Springer et al., 2008). The release of rhBMP-2 from collagen scaffolds is a clinically applicable approach to repair and regenerate critically sized craniofacial bone defects in a rat model (Sawyer et al., 2009).

Significant research activity (both pre-clinical and clinical) is currently taking place in the area of growth factor induced bone augmentation in the maxillary sinus to enable dental implant placement. In 2008, the Consensus Report of the Sixth European Workshop on Periodontology recognised that initial clinical trials support the potential of rhBMP-2 in this field, however it was emphasised that the research needed to answer questions about the clinical benefits of bone augmentation with respect to this alternative treatment (Tonetti and Hämmerle, 2008).

In the present study, the effects of rhBMP-2 on both osseointegration of dental implants and bone formation were investigated and compared with autologous pelvic cancellous bone as a filling material for sinus-floor elevation in sheep. In addition, the impact of immediate vs. secondary placement of implants, position and type of dental implants on osseointegration as well as bone density (BD) were examined.

\section{MATERIALS AND METHODS}

\section{Design and setting of the study}

This research was approved by the Animal Trial Council of the State Administration of Baden Württemberg (Germany). All surgical procedures and follow up examinations were done according to the Haas protocol (Haas et al., 1998). All the surgical procedures were carried out by the same surgeon.

A total of 9 female sheep ( $\sim 2 \frac{1}{2}$ years old) were allocated to 3 groups consisting of 3 animals each. Placement of the implants at the time of sinus augmentation was performed in two of these groups (survival time group A1: 6 weeks; $A_{2}: 12$ weeks) and in the last group the implants were placed as a secondary procedure, 6 weeks
Table 1 - Setting of the study groups

\begin{tabular}{lll}
\hline & Simultaneous implantation & $\begin{array}{l}\text { Secondary implantation } \\
\text { after 6 weeks }\end{array}$ \\
\hline 6 Weeks & 3 Sheep (group A1) & - \\
12 Weeks & 3 Sheep (group A2) & 3 Sheep (group B) \\
\hline
\end{tabular}

after the bone augmentation (survival time Group B: 12 weeks) (Table 1).

\section{Sinus floor elevation and implantation}

The sheep were operated on under general anesthesia with endotracheal intubation. After skin disinfection and sterile covering, an $8 \mathrm{~cm}$ horizontal infraorbital incision was made and the facial septum (buccal wall) of the right maxillary sinus was prepared as a test side. Access to the sinus was made $1 \mathrm{~cm}$ caudal of the infra-orbital margin through an osseous window of $1 \mathrm{~cm} \times 2 \mathrm{~cm}$. The mucosa of the sinus was elevated and the cavity between the mucosa and the inferior osseous septum of the sinus was augmented with rhBMP-2 on carrier material. Both rhBMP-2 (produced by the Genetic Institute, Cambridge, MA, USA) and poly-D, L-lactic-co-glycolic acid (PLGA)-coated gelatin sponge PLGA-coated gelatin sponge (PGS) as carrier were provided by Yamanouchi Pharmaceutical Co., Ltd (Tokyo, Japan). The PGS used as the carrier of rhBMP-2 had the following properties: $30000 \mathrm{MW}$ (molecular weight); a 1:1 molar ratio of lactic acid to glycolic acid; a 4:1 weight ratio of PLGA to gelatin; and $90 \%$ porosity. The volume of the implanted material was $3.5 \mathrm{~cm}^{3}(3.5 \mathrm{~cm} \times 1 \mathrm{~cm} \times 1 \mathrm{~cm})$. RhBMP-2 was diluted in LF 6 buffer, which consists of $5 \mathrm{mM}$ sodium glutamate, $2.5 \%$ glycine, $0.5 \%$ sucrose, and $0.01 \%$ Tween 80 with a pH of 6.5 . The rhBMP-2 concentration was $400 \mu \mathrm{g} / \mathrm{ml}$. The sponge was covered with $2 \mathrm{ml}$ of the solution, resulting in a total amount of $0.8 \mathrm{mg}$ rhBMP-2. After incubation of $30 \mathrm{~min}$, the sponge was divided in 60 equal units, which were placed into the test side. After sinus-floor elevation, three different implant systems $\left(\right.$ Straumann $^{\circledR}, 3 i^{\circledR}$ and Bränemark ${ }^{\circledR}$ ) were randomized and placed through the lateral septum in the inferior part of each sinus. Insertion of implants was performed according to the manufacturer's recommendation and with their specific drilling sets.

On the control side, the same operative procedure was followed but instead of the rhBMP-2 and poly-D, L-lacticco-glycolic acid gelatine (PLPG) sponge, $3.5 \mathrm{~cm}^{3}$ autologous pelvic bone was used for the sinus lift. The operative procedure for group A and B was identical. To mark the position for the secondary placement of implants, cortical screws were inserted $1 \mathrm{~cm}$ caudal to the planned implant site (Stardrive ${ }^{\circledR}$ 2.0, Art. Nr. 401.136, Synthes-Stratec $^{\circledR}, \quad$ Solothurn, Switzerland). See Fig. 1(A-H).

\section{Polychromic fluorescence marking}

In order to analyse weekly bone formation, vital staining of the study animals was achieved by subcutaneous 


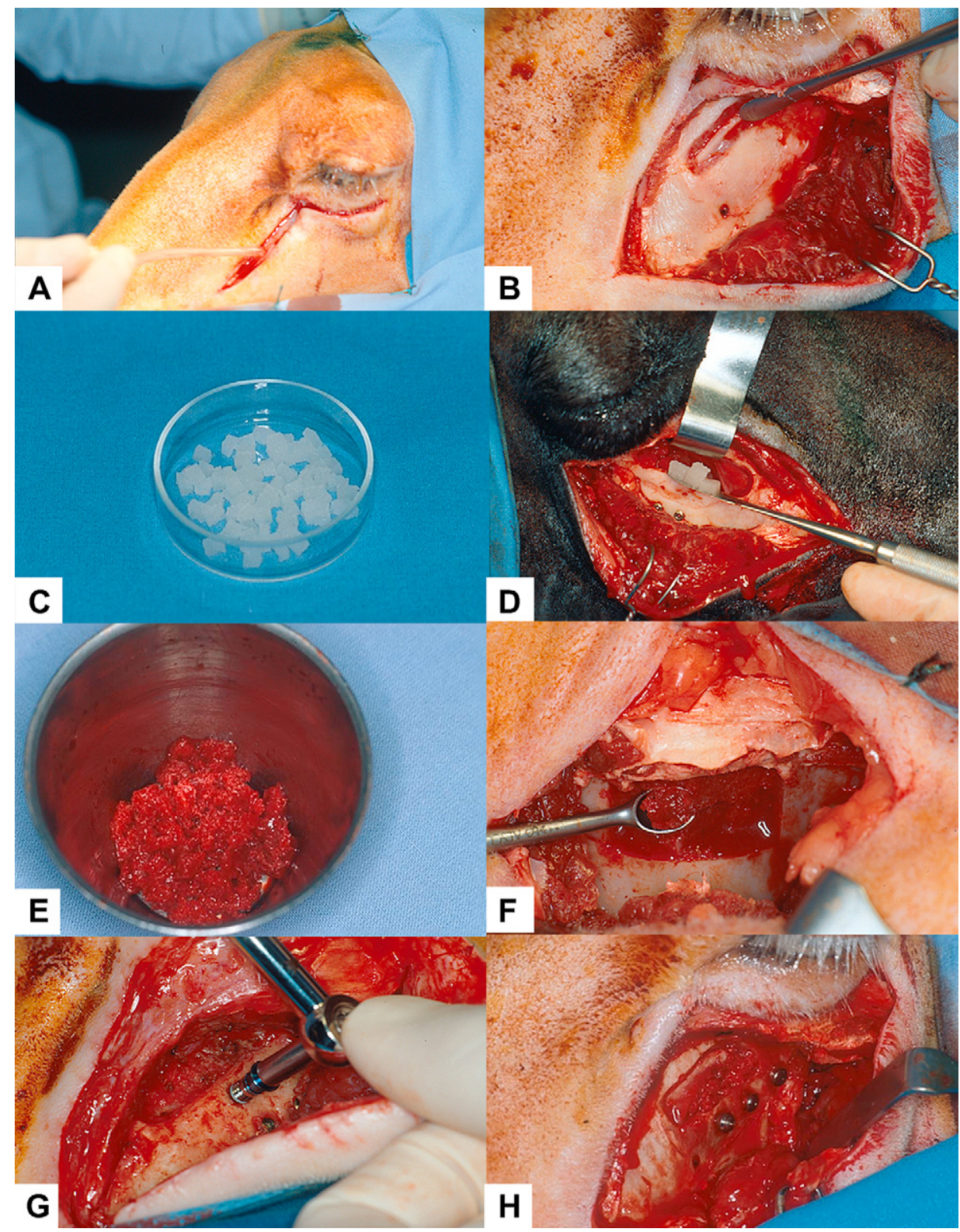

Fig. 1 - Sinus elevation surgery on sheep. A, extraoral approach to the sinus by an infraorbital incision. B, sinus window osteotomy. C, test group - preparation of rhBMP-2 with PLPG sponge. D, inserting these materials after raising the sinus membrane. E, autologous iliac bone for the control group. F, filling the sinus cavity with autologous bone. $\mathrm{G}$, implant insertion. $\mathrm{H}$, overview of the sinus augmentation and 3 different implants placement.

injection of sterile calcein and xylenol orange solution. After injection, the subcutaneous depot releases the marker for approximately one week. The pigment is integrated into the new bone during this time. Calcein $\left(\mathrm{C}_{30} \mathrm{H}_{26} \mathrm{~N}_{2} \mathrm{O}_{13}\right.$, Sigma-Aldrich, Deisenhofen, Germany), in a dosage of $10 \mathrm{mg} / \mathrm{kg}$, was administered to the group of sheep sacrificed at 6 weeks, resulting in integration of calcein (green after vital staining) in weeks two and three. Xylenol orange $\left(\mathrm{C}_{31} \mathrm{H}_{28} \mathrm{~N}_{2} \mathrm{Na}_{4} \mathrm{O}_{13} \mathrm{~S}\right.$, Sigma-Aldrich, Deisenhofen, Germany), was administered in this group at two weeks at a dose of $90 \mathrm{mg} / \mathrm{kg}$ resulting in an orange stain in weeks 4 and 5. Animals sacrificed at 12 weeks received the same dosages of calcein at weeks seven and eight (integration weeks eight and nine) and xylenol orange at weeks nine and ten (integration at weeks 10 and 11). Bone-implant contact was

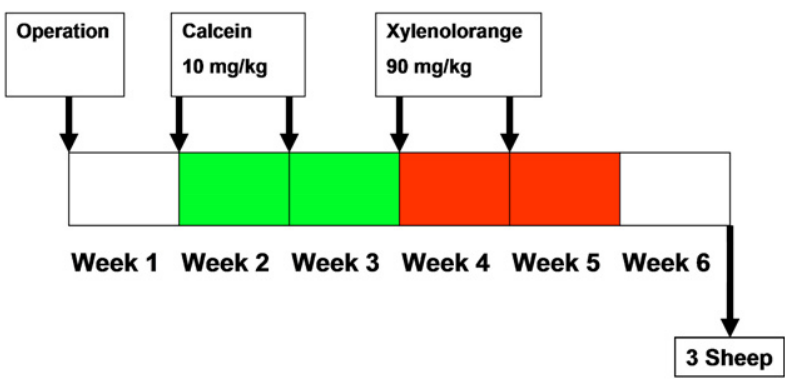

Fig. 2 - Polychromic fluorescence marking schedule for 6 week group.

measured similar to the light microscopy analysis. Figs. 2 and 3 explain the fluorescence labeling protocol.

Animals were sacrificed with i.v. premedication $100 \mathrm{mg} / \mathrm{kg}$ Pentobarbital (Narcoren ${ }^{\circledR}$, Merial GmbH, 


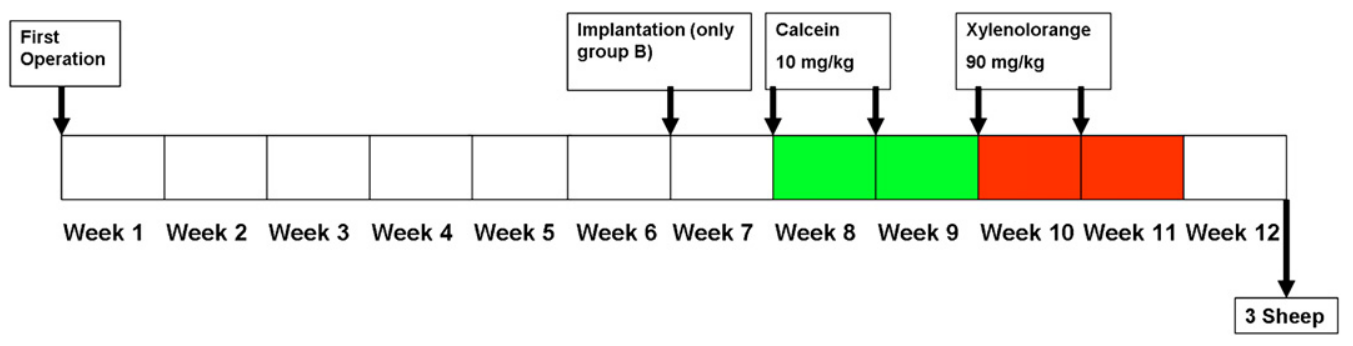

Fig. 3 - Polychromic fluorescence marking schedule for 12 week groups.

Halbergmoos, Germany) and $2 \mathrm{mmol} / \mathrm{kg}$ Kaliumchloride (Kaliumchlorid $7,45 \%$ BBraun $^{\circledR}$, BBraun, Melsungen, Germany).

\section{Histological evaluation}

Samples collected were fixated in a solution of $4 \%$ formaldehyde (Merck, Darmstadt, Germany) for 2 weeks. The technique described by Schenk was used to process the samples (Schenk, 1965). A microscope (Carl Zeiss, Göttingen, Germany) in combination with a fluorescence light source HBO 50 (Carl Zeiss, Göttingen, Germany) and a digital camera (CC-12, Soft Imaging System, Münster, Germany) was used for analysis of the prepared specimens. Staining for light microscopy was done according to the Richardson-Levai-Laczko technique with surface staining with Azure II (Merck, Darmstadt, Germany) for soft tissue visualization, surface staining with Pararosanilin (Sigma-Aldrich, Deisenhofen, Germany) for discriminating between newly generated and old bone was performed. Images were optimized and evaluated with the program Analysis (Soft Imaging System, Münster, Germany).

\section{Morphometric analysis with light microscopy and fluorescence microscopy}

Bone-to-implant contact (BIC) was measured on $80 \%$ of the apical surface of the implant. To evaluate the BD in the augmented sinus, 4 areas were defined per implant and the percentage of cancellous bone was measured (Fig. 4). These areas had a size of $2 \times 2 \mathrm{~mm}$ and were located $0.1 \mathrm{~mm}$ from the surface of the implant. By utilizing the fluorescence microscope, matching of the colored newly formed bone to the weeks of formation was possible with the following coding: calcein (purple) stained weeks 2 and 3 (6 week animals) and weeks 8 and 9 (12 week animals); xylenol orange (yellow) stained weeks 4 and 5 (6 week animals) and weeks 10 and 11 (12 week animals).

\section{Statistical analysis}

Data was evaluated using General Mixed Model Analysis of Variance; Software Excel 2002 (Microsoft $^{\circledR}$, Redmond, USA). All $p$-values were studied bilaterally with the level of significance being $p<0.05$.

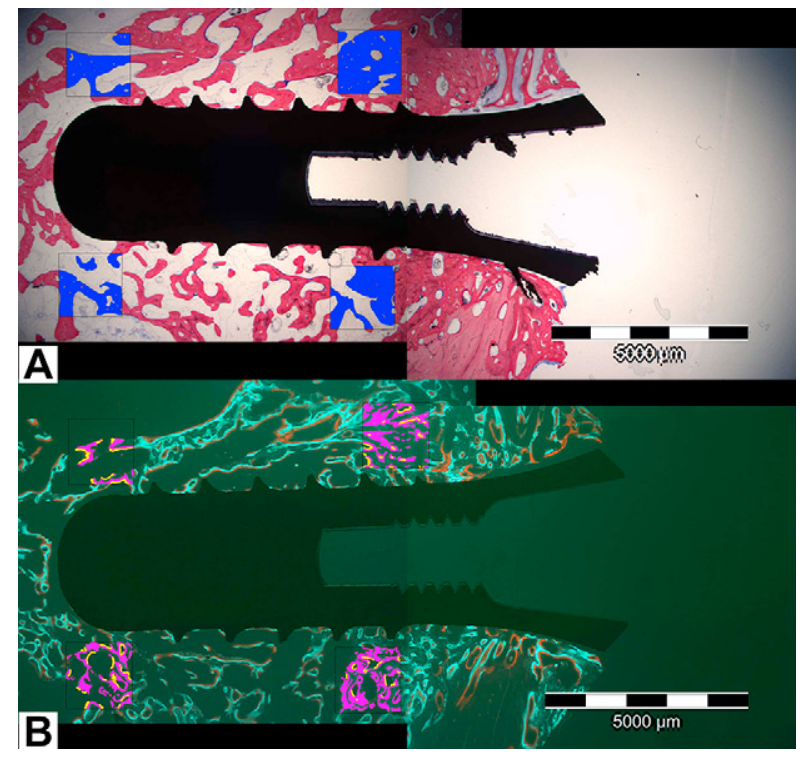

Fig. 4 - Measurement areas of BD evaluation. A, Histological and B, fluorescence staining.

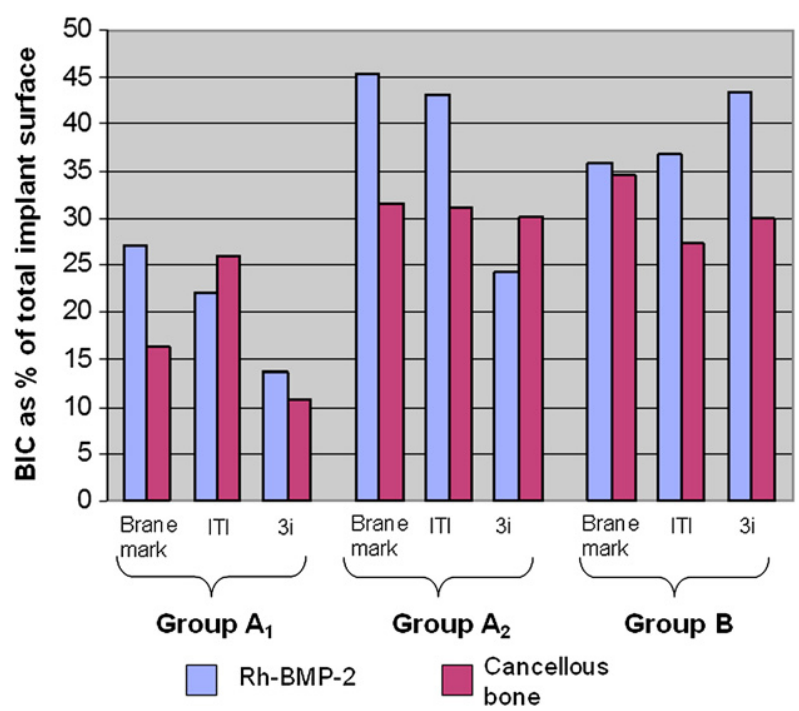

Fig. 5 - BIC on group A1, A2 and B, with different implant systems. Statistical difference found only between rhBMP-2 and control, after 12 weeks and simultaneous implantation. 
Influence of rhBMP-2 on bone formation and osseointegration 5

\section{RESULTS}

\section{Osseointegration of the implants}

\section{Morphometric analysis (light microscopy)}

The implants in the rhBMP-2 augmented sinuses had significantly higher BIC than the samples with autologous cancellous bone augmentation $(p<0.05)$. The largest difference (up to $10 \%$ ) was found after 12 weeks and with the simultaneous implantation protocol. Between weeks 6 and 12, bone-implant contact increased more on the rhBMP-2 side $(15.4 \%)$ than on the cancellous bone side $(7.7 \%)$. Fig. 5 shows BIC in different experimental groups and implant systems.

Implant systems

No statistical difference could be observed in the osseointegration between the rhBMP-2 and the cancellous bone groups on all of the three implant systems. Table 2 shows the average values and standard deviation for the implants.

\section{Implant position}

The position of the implant had no impact on osseointegration. Fig. 6 shows the average values and standard deviation for the different implant positions.

\section{Time-dependent bone formation}

In the test group sacrificed at 12 weeks most bone ( $>40 \%)$ was generated in weeks 8 and 9 (Fig. 7), while the cancellous bone side with simultaneous implantation, the majority of bone formation was between weeks 3 and 7 . In the group where implants were placed secondarily the majority of bone was formed between weeks 8 and 11 .

\section{BD in the augmented sinus}

\section{Histological and morphometric analysis}

In the group sacrificed at 6 weeks, a lower BD was measured when compared to the group sacrificed at 12 weeks with simultaneous implantation. Sinus augmentations performed with rhBMP-2 produced significantly higher bone densities in all samples with the biggest difference at 12 weeks and with simultaneous placement of the implants; $44 \% \pm 3.8 \%$ on the rhBMP-2 side and $30.9 \% \pm 8.4 \%$ on the cancellous bone side $(p<0.05)$ (Fig. 9). Fig. 8(A-F) shows the histological and fluorescence analysis in group A2 with the 3 different implant systems.

\section{Implant systems and position}

At 6 weeks the highest BD $(25.4 \%)$ could be observed on the rhBMP-2 side with the $3 \mathrm{i}$ implants. At 12 weeks with simultaneous as well as secondary implantation, the ITI implants had the highest values $(51.7 \%$ and $43.1 \%$ respectively). Overall, the difference between the systems was not statistically significant $(p>0.05)$. Positioning of the implant did not have a statistically significant effect on bone formation $(p>0.05)$.

\section{Time-dependent bone formation}

In the animals sacrificed at 6 weeks the rhBMP-2 side showed only a small amount of newly generated bone at weeks 2 and $3(3.6 \%)$ and weeks 4 and $5(9.8 \%)$. The remainder of the bone $(89.6 \%)$, however, was formed after week 5 . This compared with bone formation on the side augmented with cancellous bone; $2.9 \%$ in weeks 2 and 3 and $7.3 \%$ in weeks 4 and 5 with $89.9 \%$ after week 5 .

In the 12 week group, the rhBMP-2 side showed that the majority of bone was generated between weeks 3 and $7(65.8 \%)$ and in weeks 8 and $9(25.6 \%)$. In the cancellous bone side, $89.6 \%$ of the bone was formed between weeks 3 and 7 .

\section{DISCUSSION}

The standard procedure for sinus-floor elevation is by raising the Schneiderian membrane and filling the cavity with bone, biomaterials, or a combination of both (Thorwarth et al., 2005; Choukroun et al., 2008; Cordaro et al., 2008; Froum et al., 2008; Kirmeier et al., 2008).

The use of autologous bone during sinus augmentation has a reported success rate of over 90\% (Kent and Block, 1989; Raghoebar et al., 1993). Iliac cancellous bone is considered the gold standard regarding quantity and quality of harvested bone. The reported incidence of complications in this donor site, however, is $8 \%$ (Younger and Chapman, 1989).

Lundgren et al. (2008) reported maxillary sinus lifting using the simultaneous insertion of dental implants as tent poles. The amount of bone formation in contact with the implants seemed not to differ performing sinus membrane elevation with or without bone grafts. However, more studies should be performed to assess the long term outcomes of this technique. The use of a newly developed Space-Making device for bone reformation in maxillary sinuses has not so far resulted in bone formation (Cricchio et al., 2009).

Autologous bone grafts have an osseoinductive effect through vital osteoblasts and their precursor cells. Until recapillarisation of this tissue has occurred, the only

Table 2 - Bone to implant contact (BIC): average percentage values and standard deviation for the three different implant systems

\begin{tabular}{|c|c|c|c|c|c|c|}
\hline & \multicolumn{2}{|l|}{ Group A1 } & \multicolumn{2}{|l|}{ Group A2 } & \multicolumn{2}{|l|}{ Group B } \\
\hline & rhBMP-2 $(\%)$ & Cancellous bone $(\%)$ & rhBMP-2 $(\%)$ & Cancellous bone $(\%)$ & rhBMP-2 $(\%)$ & Cancellous bone $(\%)$ \\
\hline Brånemark & $27.0 \pm 12.6$ & $16.4 \pm 6.7$ & $45.3 \pm 6.6$ & $31.5 \pm 29.4$ & $36 \pm 19.3$ & $34.5 \pm 24.3$ \\
\hline Straumann & $22.1 \pm 17.3$ & $25.9 \pm 7.1$ & $43.2 \pm 5.5$ & $31.1 \pm 4.2$ & $36.7 \pm 19.9$ & $27.4 \pm 27.2$ \\
\hline $3 \mathrm{i}$ & $13.6 \pm 5.5$ & $10.9 \pm 5.4$ & $24.2 \pm 4.7$ & $30.2 \pm 31.8$ & $43.3 \pm 26.0$ & $30.0 \pm 24.0$ \\
\hline
\end{tabular}




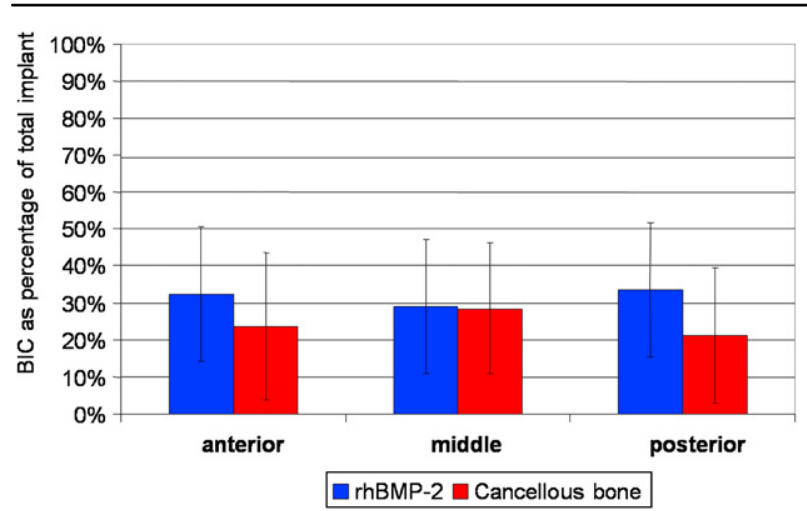

Fig. 6 - BIC in the different positions of the implants. No statistical difference was found.

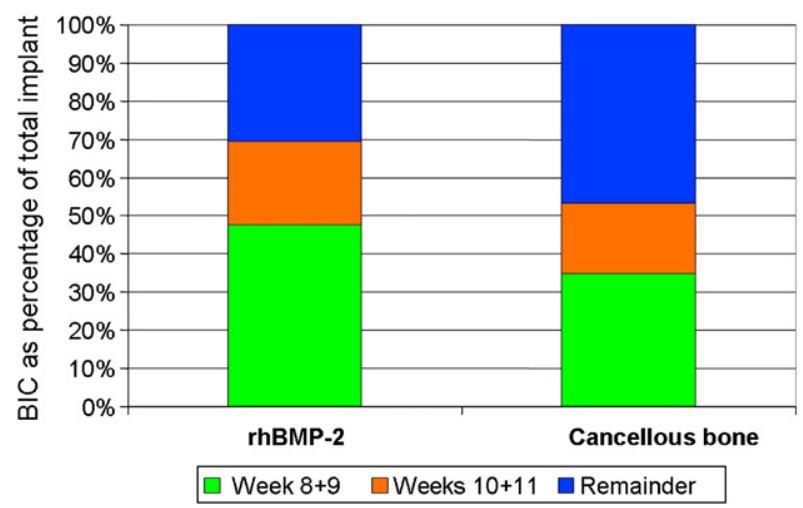

Fig. 7 - Time depending bone formation. Twelve weeks, test and control group.

nutritional supply to the cells occurs through diffusion (Kübler et al., 1999). The surviving cellular elements produce growth factors (e.g. BMPs) which have osteogenic and osseoconductive effects (Rahn and Perren, 1970; Rahn, 1976; Allegrini et al., 2003). The osseoinductive effect of rhBMP-2 depends on the amount of cells in the region of augmentation which in turn depends on the species, the age and the vascularity of the area (Terheyden et al., 1999; Yamaji et al., 2007).

Sinus-lift procedures in a sheep model are a reliable method for evaluating bone formation (Aral et al., 2008; Estaca et al., 2008). Several studies have reported the positive effects that certain BMPs have on bone generation in different animal trials (Allegrini et al., 2003, 2004.). None of these studies have, however, evaluated the use of BMPs in association with different implant systems during sinus-lift augmentation in the sheep model.

Hanisch et al. (1997) described a model in which monkeys were utilized for sinus-floor elevation with rhBMP-2 on an absorbable collagen sponge (ACS) with secondary implantation of 3 titanium implants three months after augmentation. During this study immediate placement of implants at the time of sinus elevation was not evaluated. Other studies utilized rhBMP-2 during sinus augmentation but also did not place implants simultaneously (Hanisch et al., 1997). In this study, bilateral sinus-floor elevation filled with either pelvic cancellous bone on the control side (gold standard) was compared to sinus augmentation with rhBMP-2 and an ACS on the test side with either simultaneous or secondary implantation. Rahn et al. reported on the osseoinductive effects of rhBMP-2 and autologous bone by utilizing a fluorescence marking sequence (Rahn and Perren 1970; Rahn, 1976).

During this study a total of $0.8 \mathrm{mg}$ rhBMP-2 in a concentration of $0.4 \mathrm{mg} / \mathrm{ml}$ was used while Terheyden et al. (1999) and Roldán et al. 2004 used a concentration of $0.4 \mathrm{mg} / \mathrm{ml} \mathrm{rhBMP}-7$ for their study on mini pigs, normal bone contains only $0.002 \mathrm{mg} / \mathrm{kg}$ of BMP (Rengachary, 2002). Other studies showed that large bone defects could be repaired using rhBMP-2 on a PLPG sponge (Marukawa et al., 2001). Due to its favorable structure, absorbable PLPG sponges have been used in an animal model for tracheomalacia (Nalwa et al., 2001; Sewall et al., 2003).

Previous histomorphometrical analysis of BIC were limited to smaller areas of the implant surface (Sennerby et al., 1992). During this study $80 \%$ of the implant surface was measured which increases the accuracy of the measurement (Cochran, 2000). In comparison to the 6 week group, BIC was significantly higher $(p<0.05)$ after 12 weeks in this study. At 12 weeks after sinus-floor elevation, the time of placement of the implant had no significant influence on the amount of BIC. In the rhBMP-2 side in the 6 week group, $67.7 \%$ of BIC was generated between weeks 2 and 5 . It is known that osteoprogenitor cells differentiates only 10 days after transplantation (Ripamonti and Reddi, 1994). Therefore, the remaining $32.3 \%$ of bone had to be produced during week six.

In the 12 week group, the rhBMP-2 side with simultaneous implantation, the osseointegration was twice as high in weeks 8 and 9 as in weeks 10 and 11. Therefore, the same amount of bone was generated during weeks 10 and 11 than in all the other weeks of the study combined. In the cancellous bone side, bone formation and integration were as high as in the rhBMP-2 side during weeks 2 and 3, however during weeks 4 and 5 the autogenous cancellous bone side generated much less bone. This could be interpreted as a decreasing osteogenic potency of the cancellous bone. In weeks 8 and $9,34.7 \%$ of the bone was generated in the cancellous bone side compared to the $47.6 \%$ on the rhBMP-2 side. In weeks 11 and 12, bone growth was lower on both sides (autologous bone 18.6\% and rhBMP-2 $21.9 \%$ ).

Similarly, BD within the rhBMP-2 augmented sinus was higher than on the cancellous bone side for all observation periods. The time of implant placement had no significant impact on osseointegration. BD, however, was even higher after simultaneous implant placement.

The rate of bone formation over time showed very little bone being generated in weeks 2 and 3, with slightly more in weeks 4 and 5 . The osteogenic potential of both augmentation materials was limited in the first week after sinus floor elevation. In weeks 8 and 9 , however, $25.6 \%$ 


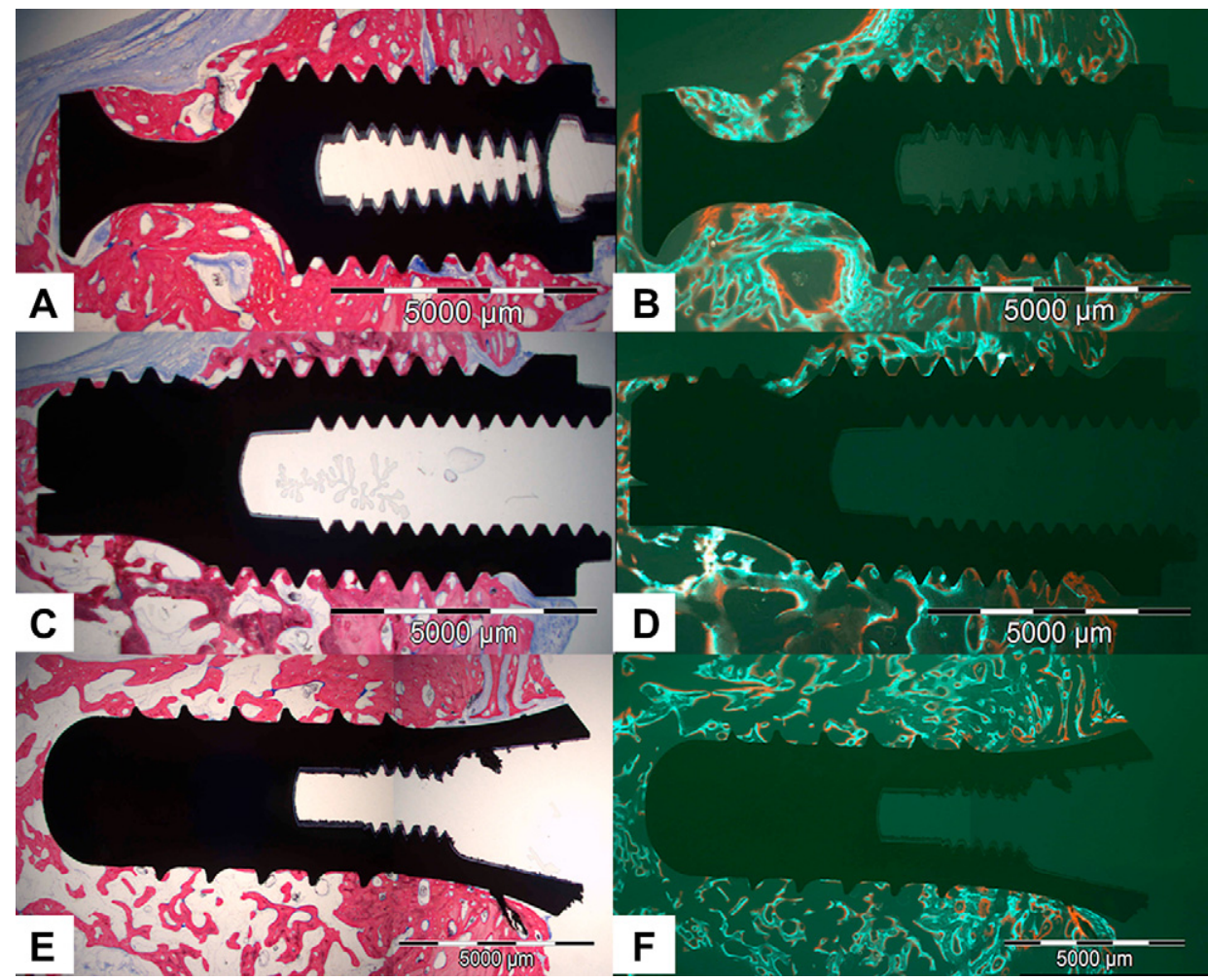

Fig. 8 - Overview of histological (A, C, E) and fluorescence (B, D, F) staining in the 12 week group with simultaneous implantation. A, B: Brånemark $^{\circledR}, \mathrm{C}, \mathrm{D}: 3 \mathrm{i}^{\circledR}, \mathrm{E}, \mathrm{F}:$ Straumann ${ }^{\circledR}$.

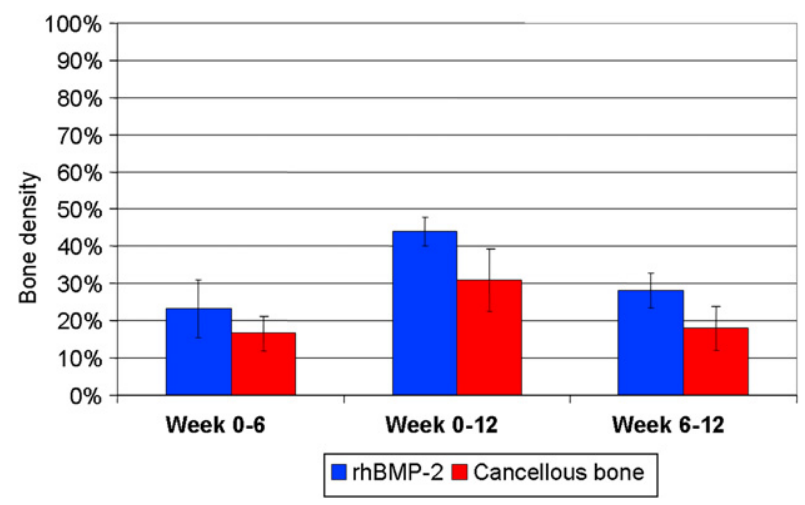

Fig. 9 - BD in the different groups.

of the new bone was generated but in weeks 10 and 11 only $8.6 \%$. These values correlate with the results of osseointegration of the implants. No differences in bone formation could be found between the immediate and secondary placement groups.

In this study, sinus-floor augmentation with rhBMP-2 had a significantly higher BIC and BD $(p<0.05)$. Another study did not show significant differences in the quantity of generated bone after sinus-floor augmentation with rhBMP-2 and cancellous bone on monkeys (Hanisch et al., 1997). The study did however show that the newly generated bone had the same quality for implant placement as the original bone. Terheyden et al. (1999) showed the impact of rhBMP-7 on osseointegration after sinus-floor augmentation in mini pigs. At 6 months, BIC was $80 \%$ on the test side and only
$38.6 \%$ on the control side (BioOss ${ }^{\circledR}$ ) (Terheyden et al., 1999; Roldán et al., 2004) compared the influence of rhBMP-7 with Platelet-Rich-Plasma (PRP) on five mini pigs. After 6 weeks, BIC was $45.8 \%$ on the rhBMP-7 side and only $5.7 \%$ on the PRP side (Roldán et al., 2004). During thus study, BIC with rhBMP-2 was only $22.2 \% \pm 12.5 \%$ at 6 weeks.

Through fluorescence marking, osseointegration of the implants on the rhBMP-2 side could be observed at 2-3 weeks. At 12 weeks, BIC was above $40 \%$ which is comparable to the normal osseointegration of dental implants. No significant correlation could be found between the position of the implant and osseointegration.

\section{CONCLUSIONS}

In sinus-floor augmentation the use of rhBMP-2 on a PLPG sponge leads to higher BD and to higher BIC but not to faster new bone formation when compared to autologous cancellous bone. The different implant types used showed no difference in osseointegration. Although the results of this study cannot be extrapolated to human subjects and further research is therefore needed, this research holds promise for the reliable and immediate placement of implants in the maxillary sinus without the need of autologous bone.

\section{References}

Allegrini Jr S, Yoshimoto M, Salles MB, König Jr B: The effects of bovine BMP associated to HA in maxillary sinus lifting in rabbits. Ann Anat 185(4): 343-349, 2003 
Allegrini Jr S, Yoshimoto M, Salles MB, König Jr B: Bone regeneration in rabbit sinus lifting associated with bovine BMP. J Biomed Mater Res B Appl Biomater 68(2): 127-131, 2004

Aral A, Yalçin S, Karabuda ZC, Anil A, Jansen JA, Mutlu Z: Injectable calcium phosphate cement as a graft material for maxillary sinus augmentation: an experimental pilot study. Clin Oral Implants Res 19(6): 612-617, 2008

Arrington ED, Smith WJ, Chambers HG, Bucknell AL, Davino NA: Complications of iliac crest bone graft harvesting. Clin Orthop Relat Res 1996;(329): : 300-309, 1996

Beloti MM, Martins Jr W, Xavier SP, Rosa AL: In vitro osteogenesis induced by cells derived from sites submitted to sinus grafting with anorganic bovine bone. Clin Oral Implants Res 19(1): 48-54, 2008

Boyne PJ, Shabahang S: An evaluation of bone induction delivery materials in conjunction with root-form implant placement. Int $\mathbf{J}$ Periodontics Restorative Dent 21(4): 333-343, 2001

Choukroun J, Simonpieri A, Del Corso M, Mazor Z, Sammartino G, Dohan Ehrenfest DM: Controlling systematic perioperative anaerobic contamination during sinus-lift procedures by using metronidazole: an innovative approach. Implant Dent 17(3): 257-270, 2008

Cochran DL: The scientific basis for and clinical experiences with Straumann implants including the ITI Dental Implant System: a consensus report. Clin Oral Implants Res 11(Suppl. 1): 33-58, 2000

Cordaro L, Bosshardt DD, Palattella P, Rao W, Serino G, Chiapasco M: Maxillary sinus grafting with Bio-Oss or Straumann Bone Ceramic: histomorphometric results from a randomized controlled multicenter clinical trial. Clin Oral Implants Res 19(8): 796-803, 2008

Cricchio G, Lundgren S: Donor site morbidity in two different approaches to anterior iliac crest bone harvesting. Clin Implant Dent Relat Res 5(3): 161-169, 2003

Cricchio G, Palma VC, Faria PE, de Oliveira JA, Lundgren S, Sennerby L, Salata LA: Histological findings following the use of a space-making device for bone reformation and implant integration in the maxillary sinus of primates. Clin Implant Dent Relat Res 2009, 2009

Estaca E, Cabezas J, Usón J, Sánchez-Margallo F, Morell E, Latorre R: Maxillary sinus-floor elevation: an animal model. Clin Oral Implants Res 19(10): 1044-1048, 2008

Froum SJ, Wallace SS, Cho SC, Elian N, Tarnow DP: Histomorphometric comparison of a biphasic bone ceramic to anorganic bovine bone for sinus augmentation: 6- to 8-month postsurgical assessment of vital bone formation. A pilot study. Int $\mathrm{J}$ Periodontics Restorative Dent 28(3): 273-281, 2008

Haas R, Mailath G, Dörtbudak O, Watzek G: Bovine hydroxyapatite for maxillary sinus augmentation: analysis of interfacial bond strength of dental implants using pull-out tests. Clin Oral Implants Res 9(2): 117-122, 1998

Hanisch O, Tatakis DN, Rohrer MD, Wöhrle PS, Wozney JM, Wikesjö UM: Bone formation and osseointegration stimulated by rhBMP-2 following subantral augmentation procedures in nonhuman primates. Int J Oral Maxillofac Implants 12(6): 785-792, 1997

Kent JN, Block MS: Simultaneous maxillary sinus floor bone grafting and placement of hydroxylapatite-coated implants. J Oral Maxillofac Surg 47(3): 238-242, 1989

Kirmeier R, Payer M, Wehrschuetz M, Jakse N, Platzer S, Lorenzoni M: Evaluation of three-dimensional changes after sinus floor augmentation with different grafting materials. Clin Oral Implants Res 19(4): 366-372, 2008

Kübler NR, Reuther JF, Faller G, Kirchner T, Ruppert R, Sebald W: Inductive properties of recombinant human BMP-2 produced in a bacterial expression system. Int J Oral Maxillofac Surg 27: 305-309, 1998

Kübler NR, Will C, Depprich R, Betz T, Reinhart E, Bill JS, Reuther JF: Comparisson of sinus elevations with autogenous or allogenous bone tissue. Mund Kiefer Gesichtschir 3: 53-60, 1999

Lundgren S, Cricchio G, Palma VC, Salata LA, Sennerby L: Sinus membrane elevation and simultaneous insertion of dental implants: a new surgical technique in maxillary sinus floor augmentation. Periodontol 2000 47: 193-205, 2008

Marukawa E, Asahina I, Oda M, Seto I, Alam MI, Enomoto S: Bone regeneration using recombinant human bone morphogenetic protein-2 (rhBMP-2) in alveolar defects of primate mandibles. Br J Oral Maxillofac Surg 39(6): 452-459, 2001

Nalwa SS, Hartig GK, Warner T, Connor NP, Thielman MJ: Evaluation of poly-lactic acid and polyglycolic acid resorbable stents for repair of tracheomalacia in a porcine model. Ann Otol Rhinol Laryngol 110(11): 993-999, 2001

Raghoebar GM, Brouwer TJ, Reintsema H, Van Oort RP: Augmentation of the maxillary sinus floor with autogenous bone for the placement of endosseous implants: a preliminary report. J Oral Maxillofac Surg 51(11): 1198-1203, 1993 discussion 1203-1205

Rahn B: Polychromic sequential marking - intra-vital marking for the in vivo analysis of bone and dentin formation German, AlbertLudwigs-Universität Freiburg, $\mathrm{PhD}$ thesis, 1976

Rahn BA, Perren SM: Calcein blue as a fluorescent label in bone. Experientia 26(5): 519-520, 1970

Rengachary S: Bone morphogenetic proteins: basic concepts. Neurosurg Focus 13(Article 2), 2002

Ripamonti U, Reddi AH: Periodontal regeneration: potential role of bone morphogenetic proteins. J Periodont Res 29: 225-235, 1994

Roldán JC, Jepsen S, Miller J, Freitag S, Rueger DC, Açil Y, Terheyden H: Bone formation in the presence of platelet-rich plasma vs. bone morphogenetic protein-7. Bone 34(1): 80-90, 2004

Sawyer AA, Song SJ, Susanto E, Chuan P, Lam CX, Woodruff MA, Hutmacher DW, Cool SM: The stimulation of healing within a rat calvarial defect by mPCL-TCP/collagen scaffolds loaded with rhBMP-2. Biomaterials 30(13): 2479-2488, 2009

Schenk R: On the histological processing of undecalcified bone. Acta Anat (Basel) 60: 3-19, 1965

Schwartz Z, Simon BJ, Duran MA, Barabino G, Chaudhri R, Boyan BD: Pulsed electromagnetic fields enhance BMP-2 dependent osteoblastic differentiation of human mesenchymal stem cells. J Orthop Res 26(9): 1250-1255, 2008

Sennerby L, Thomsen P, Ericson LE: A morphometric and biomechanic comparison of titanium implants inserted in rabbit cortical and cancellous bone. Int J Oral Maxillofac Implants 7(1): 62-71, 1992

Sewall GK, Warner T, Connor NP, Hartig GK: Comparison of resorbable poly-lactic acid-polyglycolic acid and internal Palmaz stents for the surgical correction of severe tracheomalacia. Ann Otol Rhinol Laryngol 112(6): 515-521, 2003

Silva FM, Cortez AL, Moreira RW, Mazzonetto R: Complications of intraoral donor site for bone grafting prior to implant placement. Implant Dent 15(4): 420-426, 2006

Smiler DG, Johnson PW, Lozada JL, Misch C, Rosenlicht JL, Tatum Jr OH, Wagner JR: Sinus lift grafts and endosseous implants. Treatment of the atrophic posterior maxilla. Dent Clin North Am 36(1): 151-186, 1992 discussion 187-188

Springer IN, Niehoff P, Açil Y, Marget M, Lange A, Warnke PH, Pielenz H, Roldán JC, Wiltfang J: BMP-2 and bFGF in an irradiated bone model. J Craniomaxillofac Surg 36(4): 210-217, 2008

Terheyden H, Jepsen S, Möller B, Tucker MM, Rueger DC: Sinus floor augmentation with simultaneous placement of dental implants using a combination of deproteinized bone xenografts and recombinant human osteogenic protein-1. A histometric study in miniature pigs. Clin Oral Implants Res 10(6): 510-521, 1999

Thorwarth M, Srour S, Felszeghy E, Kessler P, Schultze-Mosgau S, Schlegel KA: Stability of autogenous bone grafts after sinus lift procedures: a comparative study between anterior and posterior aspects of the iliac crest and an intraoral donor site. Oral Surg Oral Med Oral Pathol Oral Radiol Endod 100(3): 278-284, 2005

Tonetti MS, Hämmerle CH, European Workshop on Periodontology Group C: Advances in bone augmentation to enable dental implant placement: Consensus Report of the Sixth European Workshop on Periodontology. J Clin Periodontol 35(Suppl. 8): 168-172, 2008

Urist MR: Bone: formation by autoinduction. Science 150(698): 893-899, 1965

Wang EA, Rosen V, D’Alessandro JS, Bauduy M, Cordes P, Harada T, Israel DI, Hewick RM, Kerns KM, LaPan P: Recombinant human bone morphogenetic protein induces bone formation. Proc Natl Acad Sci U S A 87(6): 2220-2224, 1990 
Wozney JM: Overview of bone morphogenetic proteins. Spine 27(16 Suppl. 1): S2-S8, 2002

Yamaji K, Kawanami M, Matsumoto A, Odajima T, Nishitani Y, Iwasaka K, Yoshimitsu K, Yoshiyama M: Effects of dose of recombinant human BMP-2 on bone formation at palatal sites in young and old rats. Dent Mater J 26(4): 481-486, 2007

Yonezawa H, Harada K, Ikebe T, Shinohara M, Enomoto S: Effect of recombinant human bone morphogenetic protein-2 (rhBMP-2) on bone consolidation on distraction osteogenesis: a preliminary study in rabbit mandibles. J Craniomaxillofac Surg 34(5): 270-276, 2006

Younger EM, Chapman MW: Morbidity at bone graft donor sites. J Orthop Trauma 3(3): 192-195, 1989
Sebastian SAUERBIER, MD, DMD

Department of Oral \& Maxillofacial Surgery

Albert-Ludwigs-University, Freiburg i.Br.

Hugstetter Straße. 55

D-79106 Freiburg

Germany

Tel.: +497612704701

Fax: +497612704785

E-mail: sebastian.sauerbier@uniklinik-freiburg.de

Paper received 17 December 2008

Accepted 10 February 2010 